J. Dairy Sci. 95:5909-5915

http://dx.doi.org/10.3168/jds.2012-5321

(C) American Dairy Science Association ${ }^{\circledR}, 2012$.

\title{
Maturation of mononuclear phagocytes in the lungs of young calves-In vitro study
}

\author{
C. F. Batista, ${ }^{1}$ M. G. Blagitz, B. P. Santos, H. G. Bertagnon, A. C. Parra, R. S. Vianna, G. G. de Lucca, \\ D. M. Lima, D. S. Santos, and A. M. M. P. Della Libera \\ University of São Paulo, Faculty of Veterinary Medicine and Animal Science (FMVZ-USP), Department of Internal Medicine, \\ Av. Prof. Dr. Orlando Marques de Paiva, 87 São Paulo/SP, Brazil
}

\begin{abstract}
The influences of age in calves' immune system are described in their first phase of life. We hypothesized that variations that occur in the main mechanisms of lung innate response can help to identify periods of greater susceptibility to the respiratory diseases that affect calves in the first stage of their life. This study aimed to evaluate the innate immune system. Nine healthy calves were monitored for 3 mo and 8 immunologic evaluations were performed. Bronchoalveolar lavage samples were recovered by bronchoscopy. The alveolar macrophages in samples were identified by protein expression of cluster of differentiation 14 (CD14) and underwent functional evaluation of phagocytosis (Staphylococcus aureus stained with propidium iodide and Escherichia coli). Data was assessed by one-way ANOVA (unstacked and parametric) and the MannWhitney test (nonparametric). Functional alterations in CD14-positive phagocytes were observed, with punctual higher intensity of phagocytosis in the third week and its decrease starting at $45 \mathrm{~d}$ of life. A gradual increase in phagocytosis rate was observed starting at this date. It is concluded that from $45 \mathrm{~d}$ of life on, alveolar macrophages have less phagocytic capacity but more cells perform this function. We suggest that this occurs because lung macrophages of calves start to maintain their immune response without passive immunity influence. Until $90 \mathrm{~d}$ of life, calves did not achieve the stability to conclude the maturation of local innate immune response.
\end{abstract}

Key words: calf, phagocytosis, alveolar macrophage, innate immunity

\section{INTRODUCTION}

Calf mortality is the second cause of economic loss of cattle, being surpassed only by the losses caused by fail-

Received January 4, 2012.

Accepted April 23, 2012.

${ }^{1}$ Corresponding author: camilafb@usp.br ures in reproductive management (Kasari and Wikse, 1994). In this context, the loss of calves represents considerable economic damage, because losses compromise the rates of replacement and prevent the returns on investment from conception and birth.

Recently, concerns have been raised about effects of different management practices on the health status and weight gain of calves during pre- and postweaning. In addition to factors already known, such as adequate transfer of passive immunity and disinfection of the newborn's navel (Vasseur et al., 2010), weaning strategies (Bach et al., 2010), group composition before and after weaning (De Paula Vieira et al., 2010; Færevik et al., 2010), and the volume and type of food during preweaning (Berge et al., 2009) interfere directly with the incidence of respiratory diseases and diarrhea.

Stress has an effect on the immune system of calves, as it does in older animals. Procedures such as castration, dehorning, weaning, vaccination, and transporting are common management measures in preruminant calves and they decrease the immune system function temporarily (Cortese, 2009). This is so important that some researchers are working with different husbandry techniques to avoid stress in the young calf to try to maintain immune system integrity in the immunologically frail newborn (Nonnecke et al., 2009; Bach et al., 2010).

The respiratory tract has important defense mechanisms realized by physical barriers, by reflex coughing, sneezing and mucociliary clearance, and by cell response such as alveolar macrophages (Tizard, 2009). However, anatomical and physiological factors of the bovine respiratory tract, such as the large dead space and the interlobular septation, are responsible for reducing alveolar oxygenation and they allow pathogens to stay in the airways and contribute to the high susceptibility of the species to pneumonia (Ackermann et al., 2010). It is worse in neonates because of the slow maturation of the immune system (Cortese, 2009).

The resident alveolar macrophages are the most important cellular defense of the lungs. They are the predominant cell type in the respiratory tract, and they 
are responsible for phagocytosis of pathogens and for inflammatory mediations (Bilyk and Holt, 1993; Lohmann-Matthes et al., 1994). Lymphocytes, neutrophils, and endothelial cells are also found in bronchoalveolar lavage (BAL) and contribute to this defense (Khadom et al., 1985; Jungi et al., 1997).

This process is effective when the cells involved in local and systemic immune responses are active. Some studies have been done on the maturity of the blood immunology system (Kampen et al., 2004b), but few researchers focus on evaluating the immunology of the respiratory system, and when they do, they study specific diseases infectious in neonates and adults (Niemczuk and Bednarek, 2003; Grell et al., 2005a,b; Hagberg et al., 2005) or factors that lead to respiratory stress syndrome (Karapinar and Dabak, 2008).

The function of alveolar macrophages has been studied in pigs (Dickie et al., 2009), neonate mice (Bakker et al., 1998), adult hamsters (Kobzik et al., 1990), and adult horses (Raidal et al., 1998a,b). In bovines, some researchers have evaluated the calf respiratory system. They have emphasized the number of cells without their functions (Yeo et al., 1993).

As the maturation of the innate response of the calf lung seems to be gradual and no studies have evaluated this maturation in bovines, the aim of this study was to evaluate the function of alveolar macrophages during the first 3 mo of calf life, with the purpose of showing when this response becomes effective, to avoid management measures stressful at a time when there is immunity immaturity. For this, the monocytic phagocytes (alveolar macrophages) of BAL were collected by bronchoscopy. They were evaluated by flow cytometry. Immunophenotyping was realized through the expression of cell surface molecules (cluster of differentiation 14, CD14) and the functional evaluation of these cells was performed by phagocytosis of Staphylococcus aureus and Escherichia coli stained with propidium iodide.

\section{MATERIALS AND METHODS}

This project was approved by the Bioethics Committee of the College of Veterinary Medicine, University of São Paulo, Brazil. Nine Holstein bull calves 1 to $5 \mathrm{~d}$ of age at the beginning of the study were used. They came from dairy farms in the State of São Paulo, Brazil. All calves had total protein and $\gamma$-globulin $\geq 5.0$ and 1.0 $\mathrm{g} / \mathrm{dL}$, respectively, indicative of successful acquisition of passive immunity. The calves were allocated in the experimental center of the neonatology Clinic of Cattle and Small Ruminants FMVZ-USP. The animals were monitored daily to ensure their healthy condition during the study. No abnormalities were found upon clinical examination and blood count in these animals.
The alveolar macrophages of these calves were studied at 8 different ages during the first 3 mo of life, according to Table 1 . These cells were collected by BAL. The BAL samples were collected by endoscopy using a flexible video gastroscope (EG-250PE5 Fujinon; Fujifilm Corp., Tokyo, Japan) inserted nasopharyngeally via $60 \mathrm{~mL}$ of sterile saline solution injected through the working channel and aspirated with a vacuum cleaner, recovering approximately $50 \mathrm{~mL}$ of BAL. The samples collected were transferred to two 50-mL Falcon tubes (BD Biosciences, San Jose, CA) and sent in a cooler to the immunodiagnostic laboratory. These measures were taken to maintain cell viability and the samples were processed within $4 \mathrm{~h}$ after collection. In the laboratory, the BAL samples were centrifuged at $1,000 \times g$ for $15 \mathrm{~min}$ at $4^{\circ} \mathrm{C}$. After this, the cell button, preserved in the lower surface, was removed by sprinkling with approximately $30 \mathrm{~mL}$ of PBS. The centrifugation was repeated at $400 \times g$ for $10 \mathrm{~min}\left(4^{\circ} \mathrm{C}\right)$. After discarding the supernatant, the cells were resuspended in $1 \mathrm{~mL}$ of cell culture medium (RPMI 1640) supplemented with $10 \%$ fetal bovine serum (FBS). The cell suspension was evaluated by cell count, realized in a Neubauer chamber using the $40 \times$ magnification of an optical microscope. The cell viability was evaluated by Trypan blue exclusion. Then, the cell suspension was adjusted to $2 \times 10^{6}$ viable cells $/ \mathrm{mL}$ for the immune evaluations.

\section{Identification of the Cell Population and Evaluation of Phagocytosis}

The assays for macrophage quantification and phagocytosis in BAL were performed by flow cytometry, according to the techniques used by Hasui et al. (1989) and Kampen et al. (2004a,b). The BAL cells were collected and incubated with Staphylococcus aureus (ATCC 25923) or Escherichia coli (O98:H28) stained with propidium iodide (PI; catalog no. P4170; SigmaAldrich, St. Louis, MO). The labeled bacteria were realized as established by Hasui et al. (1989) with some modifications.

The assays were performed in polypropylene tubes for flow cytometry. In each tube was added $2 \times 10^{5}$ of

Table 1. Distribution of experimental time and age of the calves

\begin{tabular}{ll}
\hline Time & Age \\
\hline 1 & 1 wk of life \\
2 & 8 to 14 d of life \\
3 & 15 to 22 d of life \\
4 & 23 to 30 d of life \\
5 & 31 to 40 d of life \\
6 & 41 to 50 d of life \\
7 & 51 to 60 d of life \\
8 & 90 d of life \\
\hline
\end{tabular}


BAL cell suspension $(100 \mu \mathrm{L})$ from each animal. It was incubated at $37^{\circ} \mathrm{C}$ for $30 \mathrm{~min}$ with $100 \mu \mathrm{L}$ of Staph. aureus or E. coli (25 bacteria per cell) labeled with PI. After the incubation period, the reactions were stopped with 2,000 $\mu \mathrm{L}$ of cold solution of EDTA $(3 \mathrm{mM})$; then, the tubes were centrifuged at $250 \times g$ for $8 \mathrm{~min}$.

After centrifuging and discarding the supernatant, $1 \mu \mathrm{L}$ of monoclonal antibody mouse IgG1 anti-bovine CD14 (catalog no. MM61A; VMRD Inc., Pullman, WA) was added to tubes. The tubes were kept at room temperature for $30 \mathrm{~min}$. After this, $1,000 \mu \mathrm{L}$ of cold PBS was added and a new centrifugation was performed (250 $\times g$ for $8 \mathrm{~min}$ ). The supernatant was discarded and 1 $\mu \mathrm{L}$ of monoclonal antibody secondary goat anti-mouse IgG1 conjugated to fluorochrome allophycocyanin (APC; catalog no. A10541; Invitrogen Corp., Carlsbad, CA) was added. The samples were kept at room temperature in the dark for $30 \mathrm{~min}$. After this, the samples were washed again and resuspended with $300 \mu \mathrm{L}$ of cold solution of PBS + BSA and kept in the dark until being read in the FACSCalibur flow cytometer (Becton Dickinson Immunocytometry Systems, San Diego, CA). The samples were read in a flow cytometer connected to a computer with CellQuest software (Becton Dickinson Immunocytometry Systems); 50,000 events were acquired from each tube and the data obtained were analyzed by FlowJo software (Tree Star Inc., Ashland, OR; version 7.6.1 for Windows).

The localization of macrophage populations of BAL samples was performed by dot plot with size (FSC) and granularity (SSC; Lohmeyer et al., 1994; Raidal et al., 1998a). After the identification and selection of macrophage populations by gate, they were identified by CD14 (APC) expression through the average fluorescence intensity obtained on a logarithmic scale with wavelength $661 \pm 16 \mathrm{~nm}$ (FL4) demonstrated in picture 1 of Figure 2.

The CD14 label was used because the cell suspensions of all BAL cells were labeled with CH138 monoclonal antibody and a population was labeled with CD14. To verify which cell was labeled, the cell suspensions of BAL were separated by flotation using a Ficoll gradient. The mononuclear cells were confirmed by optical microscope and incubated with both antibodies (CH138 and CD14). These cell populations were double labeled. The polymorphonuclear cells were isolated and confirmed in the same manner and also incubated with both antibodies. These cells were not labeled with CD14, just with CH138. Thus, we concluded that the CD14-positive cells were mononuclear cells. As most of the cell suspensions of BAL were macrophages, we prefer to characterize them as alveolar macrophages.

Phagocytosis was measured by emission of red fluorescence at wavelength $670 \mathrm{~nm}$ (FL3) for PI. The values were analyzed after compensation of fluorescence to avoid the crossing of waves.

\section{Statistical Analysis}

Statistical analysis was performed using the statistical software GraphPad InStat version 3.01 for Windows 95 (GraphPad Software Inc., San Diego, CA). The normality of the distribution was verified by the Anderson-Darling test. To evaluate the differences be-

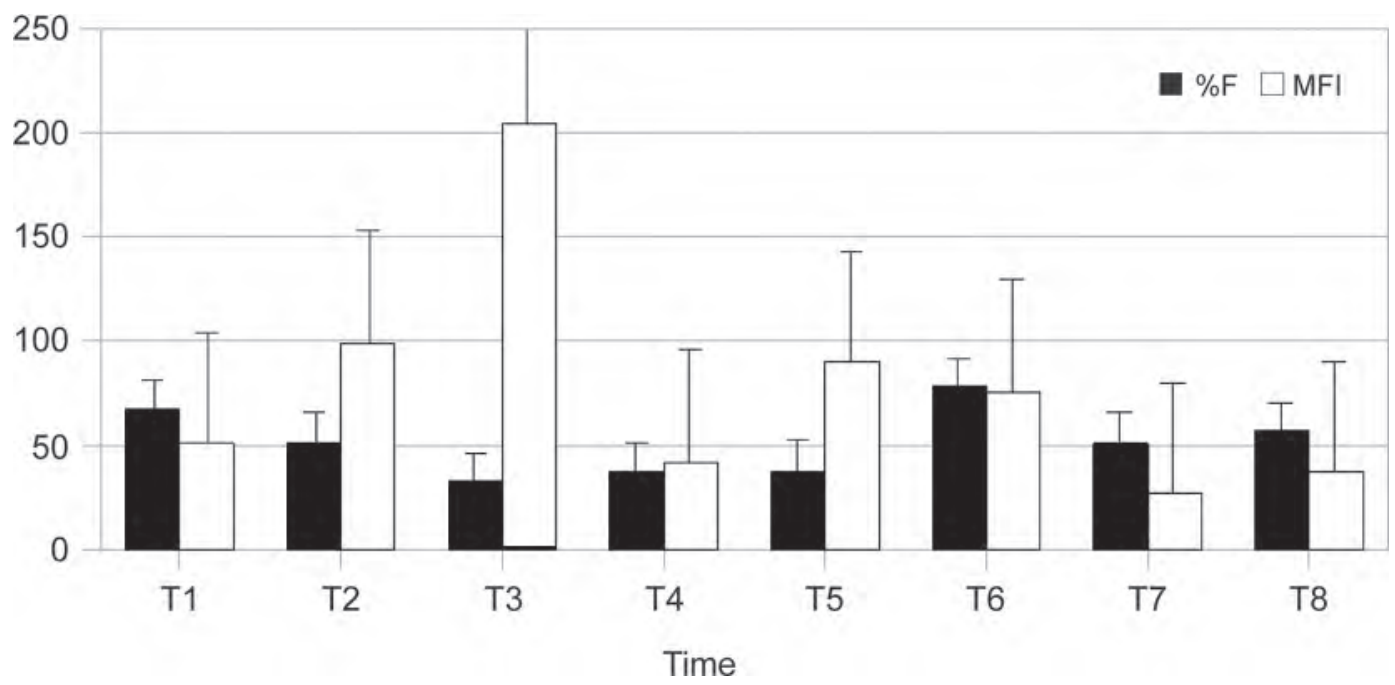

Figure 1. Staphylococcus aureus phagocytosis (percent fluorescence, $\% \mathrm{~F}$ ) and mean fluorescence intensities (MFI) on calf bronchoalveolar lavage (BAL) cluster of differentiation 14 (CD14)-positive macrophages in the first 3 mo of life. Data are expressed as means and error bars represent standard errors of the means $(\mathrm{n}=9)$. $\mathrm{T} 1=1 \mathrm{wk}$ of life; T2 $=8$ to $14 \mathrm{~d}$ of life; T3 $=15$ to $22 \mathrm{~d}$ of life; T4=23 to $30 \mathrm{~d}$ of life; T5 $=$ 31 to $40 \mathrm{~d}$ of life; $\mathrm{T} 6=41$ to $50 \mathrm{~d}$ of life; $\mathrm{T} 7=51$ to $60 \mathrm{~d}$ of life; T8 $=90 \mathrm{~d}$ of life. 


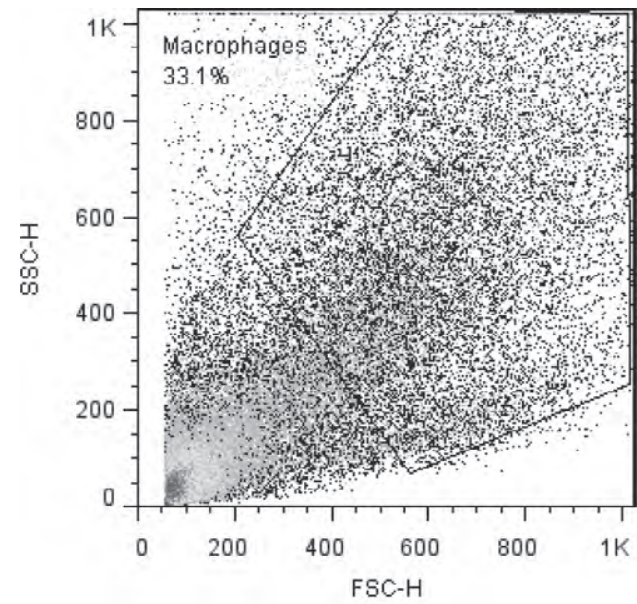

a)

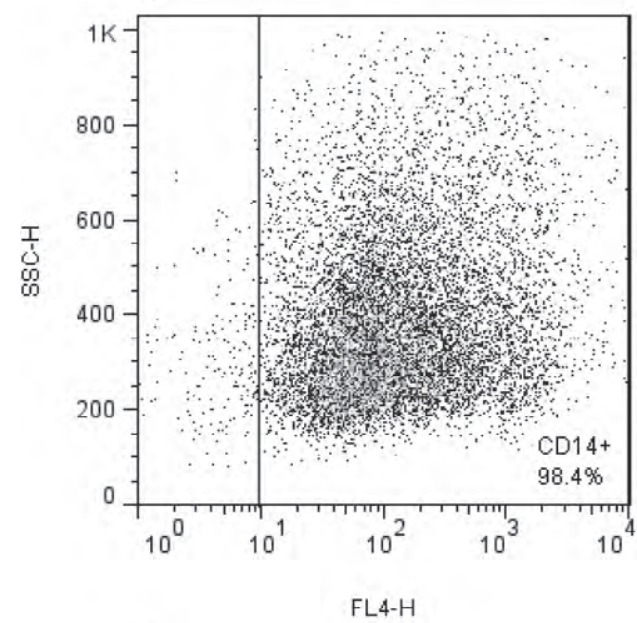

b)

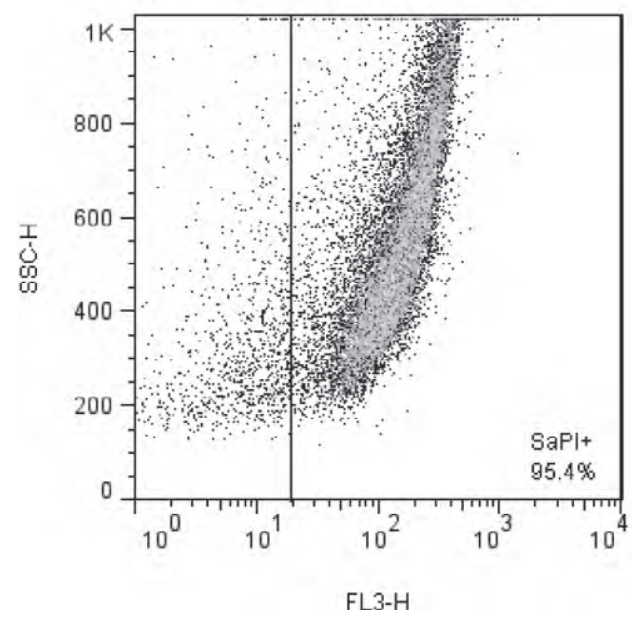

Figure 2. Examples of identification of bronchoalveolar lavage (BAL) macrophages. The top picture indicates the cell selection in relation to leukocytes. Picture (a) indicates the population that is expressing cluster of differentiation 14 (CD14+). Picture (b) indicates the CD14+ population that phagocytized Staphylococcus aureus (São Paulo, Brazil; 2010). SSC-H = side scatter; FSC-H = forward scatter; FL3-H = fluorescent labels 3; FL4-H = fluorescent labels 4; SaPI+ = population that phagocytized Staphylococcus aureus with propidium iodide. tween the averages of the results, tests were performed using one-way ANOVA (unstacked; for data with a normal distribution) and the Mann-Whitney test (for data without a normal distribution). When $P<0.05$, statistical difference was detected.

\section{RESULTS AND DISCUSSION}

This study sought to establish inclusion and exclusion criteria for samples that would ensure the subsequent maturation of the immune system without stress interference. Thus, changes in local phagocytes would be possible, following the longitudinal dynamics of the most important aspects of the airway defenses of calves, besides answering the original question: is there age variation in immune efficiency in the calf lungs in the first $3 \mathrm{mo}$ ?

\section{BAL Macrophage Immunophenotyping}

To identify BAL cell populations, flow cytometry was used, which allows allocation of the cell types through cell count. The population distribution of blood cell counts has well-defined localization based on the size and complexity of leukocytes. This does not happen with BAL cells, which show dispersed populations (Barry et al., 2002; Soethout et al., 2004).

Based on these data, gate selection was done according to Lohmeyer et al. (1994), Raidal et al. (1998a), and Soethout et al. (2004) to use selection population macrophage cells. To confirm the cell type in this selected gate, immunophenotyping was performed using the CD14 population, which is expressed mainly by the monocytic macrophage lineage cells.

Most of the cell respiratory system comprises macrophages, which are large and have low granularity. However, in this study, a low percentage of these cells were found in the gate and their amounts did not vary with animal age (variation was 12.52 to $21.56 \%$ macrophage; $P=0.67)$.

According to Raidal et al. (1998b), probably the cells in the gate are macrophages and other cells that are not macrophages (epithelial and large lymphocytes) or other subpopulations of macrophages that perform different functions beyond phagocytosis and do not express CD14. This could be noticed with the percentage from 38 to $79 \%$ of the CD14-positive macrophages analyzed in the selected gate.

\section{Phagocytosis}

The function of macrophages is to phagocytize microbial products and destroy cells in the alveolar space. 
They secrete proinflammatory cytokines and present antigens to T helper lymphocytes (Tizard, 2009).

Phagocytosis is an innate immune defense that is defined by the activation of complex signaling networks that are stimulated by contact with a microorganism (Underhill and Ozinsky, 2002). In the phagocytosis assay, Escherichia coli and Staphylococcus aureus labeled with propidium iodide were used. Although this marking technique provided satisfactory results, fluorescence intensity might vary between different labeling batches (Raidal et al., 1998b). To solve this problem, both bacteria were labeled with same protocol, at same time, and in the same batch.

\section{Staphylococcus aureus Phagocytosis}

A difference in Staphylococcus aureus phagocytosis was observed by percent fluorescence for the different times $(P=0.0036)$. The percent fluorescence of cells at T6 (41 to $50 \mathrm{~d}$ of life) was higher than that at T3 (15 to $22 \mathrm{~d}$ of life), T4 (23 to $30 \mathrm{~d}$ of life), and T5 (31 to 40 $\mathrm{d}$ of life). This difference was not observed for cells at the other times. The average intensity values of phagocytosis observed by mean fluorescence intensity (MFI) showed differences $(P=0.03)$ between the times. The MFI at T3 was higher than that at T4 and T7 (51 to $60 \mathrm{~d}$ of life). The difference was not observed for the other times.

Figure 1 shows the mean values and standard deviations of BAL CD14-positive macrophages that phagocytized Staphylococcus aureus. Figure 2 shows examples of calf BAL CD14-positive macrophage identification and the one that phagocytized Staphylococcus aureus.

\section{Escherichia coli Phagocytosis}

A difference in Escherichia coli phagocytosis was observed by percent fluorescence $(\% \mathrm{~F})$ for the different times $(P=0.04)$. The percent fluorescence of $\mathrm{T} 6$ was higher than T4. This difference was not observed for the other times. The average values of the intensity of phagocytosis observed by MFI showed differences $(P$ $=0.03$ ) between the times. The MFI of T3 was higher than that of T7. The difference was not observed for the other times.

Figure 3 shows the mean values and standard deviations of BAL CD14-positive macrophages that phagocytized Escherichia coli. Figure 4 shows examples of calf BAL CD14-positive macrophages identification and the one that phagocytized Escherichia coli.

The results of Staphylococcus aureus phagocytosis showed lower percentages from the third week of life until $40 \mathrm{~d}$ of life (T3 to T5). In this time, a large quantity of colostral immunoglobulins was responsible for the defense of the respiratory system (data not shown). In the first $2 \mathrm{wk}$ of life (T1 and T2), the percentage of phagocytosis was high. This is explained by colostral cytokines: after their absorption by the calf, they migrate to the circulation and stimulate immune cell activity in all tissues, mainly in the respiratory system for a short period (Ackermann et al., 2010).

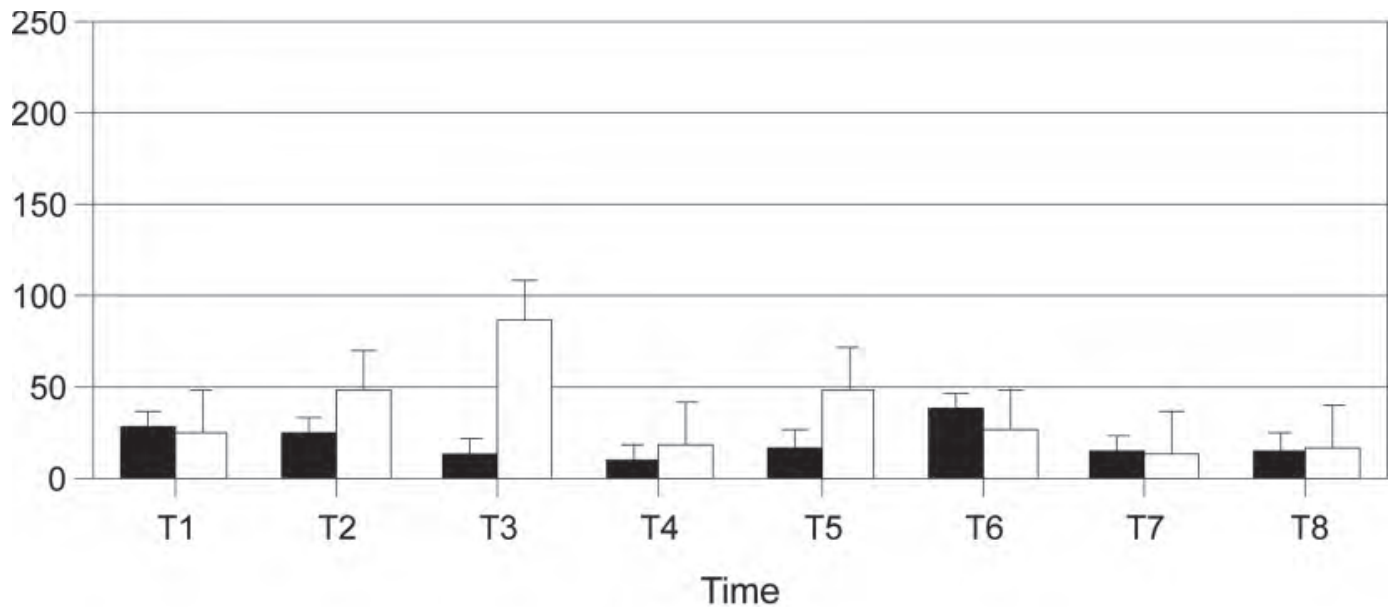

\%F $\square \mathrm{MFI}$

Figure 3. Escherichia coli phagocytosis (percent fluorescence, $\% \mathrm{~F}$ ) and mean fluorescence intensities (MFI) on calf bronchoalveolar lavage (BAL) cluster of differentiation 14 (CD14)-positive macrophages in the first 3 mo of life. Data are expressed as means and error bars represent standard errors of the means $(\mathrm{n}=9)$. T $1=1 \mathrm{wk}$ of life; T2 $=8$ to $14 \mathrm{~d}$ of life; T3 $=15$ to $22 \mathrm{~d}$ of life; T4 $=23$ to $30 \mathrm{~d}$ of life; T5 $=31$ to 40 $\mathrm{d}$ of life; $\mathrm{T} 6=41$ to $50 \mathrm{~d}$ of life; $\mathrm{T} 7=51$ to $60 \mathrm{~d}$ of life; $\mathrm{T} 8=90 \mathrm{~d}$ of life. 
When the percent fluorescence of Staphylococcus aureus was evaluated, it was observed that cells in the third week of life (T3) had higher MFI. This is explained by higher-efficiency cells, although few cells had done phagocytosis. However, at $60 \mathrm{~d}$ of life (T7) they had lower MFI, but a higher percent fluorescence, which suggests an immunological window during this period. The same occurred in the E. coli assay, but at a lower intensity.

The maturing of the bovine immune system occurs between the fifth and eighth months of life. In this phase of life, the animals are able to respond to a pathogen, but the response is weaker, slower, and less effective than that of animals with mature immune systems (Cortese, 2009). In the current study, the animals showed a reduced capacity of phagocytosis between the third and fifth weeks of life. At this time, they have colostral immunity, which is extremely important in preventing disease. After the sixth week (T6) of life, colostral immunity declined and phagocytosis increased, but not to maximum capacity. In this period, the animal can be more susceptible to infections.

Similar results were reported by Grell et al. (2005a,b) and Antonis et al. (2010) when these authors studied bovine syncytial virus in newborn calves and young calves. Calves at 16 wk of age had mainly cellular responses, with clinical symptoms and lung tissue damage more evident, and a low rate of viral clearance. It was more intense between 9 and 16 wk of age compared with younger ages. The low rate of viral clearance resulted from the capacity of the cellular immune response in this period, confirming the results of the current study.

Moreover, it is at this age, when there is greater dependence on active immune response, that calves are weaning. The weaning of dairy calves is based on the calf's ability to eat solid food, which occurs at about 49 to $60 \mathrm{~d}$ of age. Researchers are concerned about ways to reduce the stress of weaning, but they do not speculate about whether the calf is experiencing immunological immaturity in this time (Bach et al., 2010; De Paula Vieira et al., 2010; Vasseur et al., 2010). As stress is known to influence both adaptive and innate immune responses in both young and adult animals (Cortese, 2009), stressful measures should be avoided in this period critical for mature immunity, so the age of weaning should be well considered. Hulbert et al. (2011) observed that calves weaned early (3.7 d of age) are generally more stressed than conventionally weaned calves (44.7 d of age), and they have more suppression of the innate immune response; however, the immunological results in resistance to disease are not known because calves weaned early have greater humoral protection from passively derived immunoglobulins.
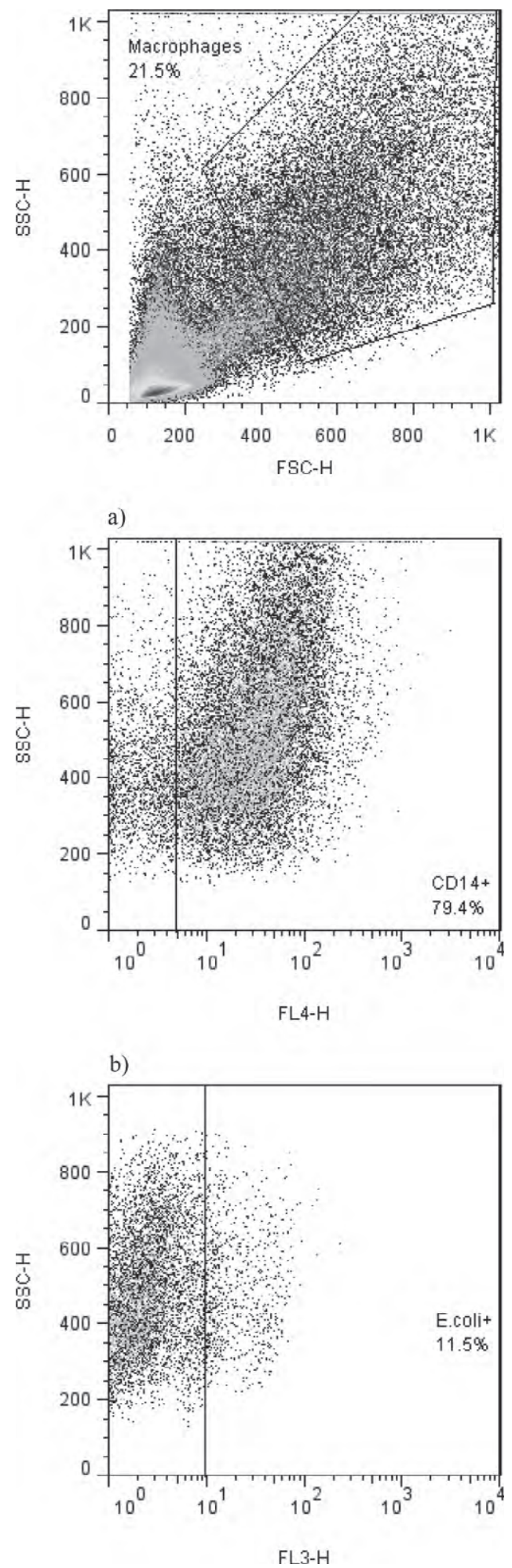

Figure 4. Examples of identification of bronchoalveolar lavage (BAL) macrophages. The top picture indicates the cell selection in relation to leukocytes. Picture (a) indicates the population that is expressing cluster of differentiation 14 (CD14+). Picture (b) indicates the CD14+ population that phagocytized Escherichia coli (São Paulo, Brazil; 2010). SSC-H = side scatter; FSC-H = forward scatter; FL3-H $=$ fluorescent labels $3 ; \mathrm{FL} 4-\mathrm{H}=$ fluorescent labels 4. 


\section{CONCLUSIONS}

We concluded that variation exists in the innate immune function of healthy calves at different times. Innate immune functions did not reach maturity in the first 3 mo of age, but how this interferes with immune response is unknown because elements of the innate response other than macrophages are important, too. The specific changes were observed at $21 \mathrm{~d}$ of life, but they were more evident from $60 \mathrm{~d}$ of life.

\section{ACKNOWLEDGMENTS}

This study was supported by the Foundation for Research Support of São Paulo (FAPESP 2009/06013-1).

\section{REFERENCES}

Ackermann, M. R., R. Derscheid, and J. A. Roth. 2010. Innate immunology of bovine respiratory diseases. Vet. Clin. North Am. Food Anim. Pract. 26:215-228.

Antonis, A. F. G., M. C. de Jong, W. H. M. van der Poel, R. G. van der Most, N. Stockhofe-Zurwieden, T. Kimman, and R. S. Schrijver. 2010. Age-dependent differences in the pathogenesis of bovine respiratory syncytial virus infections related to the development of natural immunocompetence. J. Gen. Virol. 91:2497-2506.

Bach, A., J. Ahedo, and A. Ferrer. 2010. Optimizing weaning strategies of dairy replacement calves. J. Dairy Sci. 93:413-419.

Bakker, J. M., E. Broug-Holub, H. Kroes, E. P. van Rees, G. Kraal, and J. F. van Iwaarden. 1998. Functional immaturity of rat alveolar macrophages during postnatal development. Immunology 94:304-309.

Barry, S. M., A. Condez, M. A. Johnson, and G. Janossy. 2002. Determination of bronchoalveolar lavage leukocyte populations by flow cytometry in patients investigated for respiratory disease. Cytometry 50:291-297.

Berge, A. C. B., T. E. Besser, D. A. Moore, and W. M. Sischo. 2009. Evaluation of the effects of oral colostrum supplementation during the first fourteen days on the health and performance of preweaned calves. J. Dairy Sci. 92:286-295.

Bilyk, N., and P. G. Holt. 1993. Inhibition of the immunosuppressive activity of resident pulmonary alveolar macrophages by granulocyte/macrophage colony-stimulating factor. J. Exp. Med. $177: 1773-1777$.

Cortese, V. S. 2009. Neonatal immunology. Vet. Clin. North Am. Food Anim. Pract. 25:221-227.

De Paula Vieira, A., M. A. G. von Keyserlingk, and D. M. Weary. 2010. Effects of pair versus single housing on performance and behavior of dairy calves before and after weaning from milk. J. Dairy Sci. 93:3079-3085.

Dickie, R., D. R. Tasat, E. Fernandez Alanis, V. Delfosse, and A. L. Tsuda. 2009. Age-dependent changes in porcine alveolar macrophage function during the postnatal period of alveolarization. Dev. Comp. Immunol. 33:145-151.

Færevik, G., M. B. Jensen, and K. E. Bøe. 2010. The effect of group composition and age on social behavior and competition in groups of weaned dairy calves. J. Dairy Sci. 93:4274-4279.

Grell, S. N., U. Riber, K. Tjørnehøj, L. E. Larsen, and P. M. H. Heegaard. 2005a. Age-dependent differences in cytokine and antibody responses after experimental RSV infection in a bovine model. Vaccine 23:3412-3423.

Grell, S. N., K. Tjørnehøj, L. E. Larsen, and P. M. H. Heegaard. 2005b. Marked induction of IL-6, haptoglobin and IFN $\gamma$ following experimental BRSV infection in young calves. Vet. Immunol. Immunopathol. 103:235-245.
Hagberg, M., E. Wattrang, R. Niskanen, M. Tråvén, J. Höglund, and A. Lundén. 2005. Mononuclear cell subsets in bronchoalveolar lavage fluid during Dictyocaulus viviparus infection of calves: A potential role for $\gamma / \delta$ TCR-expressing cells in airway immune responses? Parasite Immunol. 27:151-161.

Hasui, M., Y. Hirabayashi, and Y. Kobayashi. 1989. Simultaneous measurement by flow cytometry of phagocytosis and hydrogen peroxide production of neutrophils in whole blood. J. Immunol. Methods 117:53-58.

Hulbert, L. E., C. J. Cobb, J. A. Carroll, and M. A. Ballou. 2011. The effects of early weaning on innate immune responses of Holstein Calves. J. Dairy Sci. 94:2545-2556.

Jungi, T. W., H. Sager, H. Adler, M. Brcic, and H. Pfister. 1997. Serum factors, cell membrane CD14, and $\beta_{2}$ integrins are not required for activation of bovine macrophages by lipopolysaccharide. Infect. Immun. 65:3577-3584.

Kampen, A. H., T. Tollersrud, S. Larsen, J. A. Roth, D. E. Frank, and A. Lund. 2004a. Repeatability of flow cytometric and classical measurement of phagocytosis and respiratory burst in bovine polymorphonuclear leukocytes. Vet. Immunol. Immunopathol. 97:105-114.

Kampen, A. H., T. Tollersrud, and A. Lund. 2004b. Flow cytometric measurement of neutrophil respiratory burst in whole bovine blood using live Staphylococcus aureus. J. Immunol. Methods 289:47-55.

Karapinar, T., and M. Dabak. 2008. Treatment of premature calves with clinically diagnosed respiratory distress syndrome. J. Vet. Intern. Med. 22:462-466.

Kasari, T. R., and S. E. Wikse. 1994. Perinatal mortality in beef herds. Vet. Clin. North Am. Food Anim. Pract. 10:1-185.

Khadom, N. J., J. F. Dedieu, and M. Viso. 1985. Bovine alveolar macrophage: A review. Ann. Rech. Vet. 16:175-183.

Kobzik, L., J. J. Godleski, and J. D. Brain. 1990. Selective down regulation of alveolar macrophage oxidative response to opsonin-independent phagocytosis. J. Immunol. 144:4312-4319.

Lohmann-Matthes, M.-L., C. Steinmüller, and G. Franke-Ullmann. 1994. Pulmonary macrophages. Eur. Respir. J. 7:1678-1689.

Lohmeyer, J., J. Friedrich, S. Rosseau, H. Pralle, and W. Seeger. 1994. Multiparameter flow cytometric analysis of inflammatory cells contained in bronchoalveolar lavage fluid. J. Immunol. Methods 172:59-70.

Niemczuk, K., and D. Bednarek. 2003. Changes in the peripheral leukocyte phenotype of calves in clinical cases of bronchopneumonia complicated with chlamydial co-infectious agent. Pol. J. Vet. Sci. $6: 125-129$.

Nonnecke, B. J., M. R. Foote, B. L. Miller, M. Fowler, T. E. Johnson, and R. L. Horst. 2009. Effects of chronic environmental cold on growth, health, and select metabolic and immunologic responses of preruminant calves. J. Dairy Sci. 92:6134-6143.

Raidal, S. L., G. D. Bailey, and D. N. Love. 1998a. The flow cytometric evaluation of phagocytosis by equine peripheral blood neutrophils and pulmonary alveolar macrophages. Vet. J. 156:107-116.

Raidal, S. L., G. D. Bailey, and D. N. Love. 1998b. Flow cytometric determination of oxidative burst activity of equine peripheral blood and bronchoalveolar lavage-derived leucocytes. Vet. J. 156:117-126.

Soethout, E. C., K. E. Müller, A. J. M. van den Belt, and V. P. M. G. Rutten. 2004. Identification and phenotyping of leukocytes in bovine bronchoalveolar lavage fluid. Clin. Diagn. Lab. Immunol. 11:795-798.

Tizard, I. R. 2009. Veterinary immunology: An introduction. 8th ed. Elsevier, St. Louis, MO.

Underhill, D. M., and A. Ozinsky. 2002. Phagocytosis of microbes: Complexity in action. Annu. Rev. Immunol. 20:825-852.

Vasseur, E., F. Borderas, R. I. Cue, D. Lefebvre, D. Pellerin, J. Rushen, K. M. Wade, and A. M. de Passillé. 2010. A survey of dairy calf management practices in Canada that affect animal welfare. J. Dairy Sci. 93:1307-1315.

Yeo, S. P., C. R. Stokes, F. G. R. Taylor, and F. J. Bourne. 1993 Maturation of cellular defence in the respiratory tract of young calves. Res. Vet. Sci. 55:292-297. 